Short Communication

\title{
Corrosion of Weathering Steel under Light Illumination and Simulated Atmospheric Conditions
}

\author{
Xiangxiao Qiu*, Jifeng Li, Zhanqing Liu \\ College of Chemistry and Material of WeiNan Normal University, Weinan 714099, China \\ "E-mail: xiangxiaoqiu18@sohu.com
}

doi: $10.20964 / 2019.04 .36$

Received: 7 December 2018 / Accepted: 16 January 2019 / Published: 10 March 2019

\begin{abstract}
Earlier investigations have shown that corrosion products of weathering steel presented photovoltaic effect under illumination. In this study, we explored the influence of chloride ions on this effect and the related corrosion behavior. Open circuit potential, electrochemical impedance spectroscopy and MottSchottky plots were recorded on weathering steel surface treated with $\mathrm{NaCl}$ after 3 days exposure in simulated atmospheric condition under illumination. For comparison, similar study was also performed on the weathering steel surface without $\mathrm{NaCl}$ deposition. There was clearly photoelectrochemical response difference between the samples. It was found that the defects concentration and electric conductivity of the corrosion products were higher due to the chloride ions migration, which was promoted by incorporation of photo-generated holes under illumination. The detailed mechanism was discussed in this study.
\end{abstract}

Keywords: atmospheric corrosion; chloride ions migration; photovoltaic effect

\section{$\underline{\text { FULL TEXT }}$}

(C) 2019 The Authors. Published by ESG (www.electrochemsci.org). This article is an open access article distributed under the terms and conditions of the Creative Commons Attribution license (http://creativecommons.org/licenses/by/4.0/). 